\title{
Influence of Operating Parameters and System Design on Efficiency of Biomass and Biogas Based SOFC Systems
}

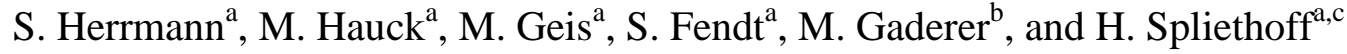 \\ ${ }^{a}$ Institute for Energy Systems, Technical University of Munich, 85748 Garching, \\ Germany \\ ${ }^{\mathrm{b}}$ Regenerative Energy Systems, Technical University of Munich, 94315 Straubing, \\ Germany \\ ${ }^{\mathrm{c}}$ ZAE Bayern, 85748 Garching, Germany
}

The presented work investigates utilization of biogas and syngas from biomass gasification in different system designs. This is done using a thermodynamic SOFC model built in Aspen Plus. With the model, the influence of different fuel pre-treatment and prereforming options are compared at a fixed stack size. Furthermore the effect of anode off-gas recirculation, as well as the choice of fuel utilization are studied. Results show, that depending on the fuel, system design and parameters the electrical efficiency of the fuel cell alone can vary between 35 and $71 \%$. System AC net efficiencies reach from 30 to $64 \%$. Finally a new system configuration is investigated, which is based on recovery of $\mathrm{H}_{2}$ from the anode exhaust using a water gas shift membrane. For this new configuration an efficiency of $73 \%$ is calculated.

\section{Introduction}

With the recent COP 21 declaration many countries have dedicated themselves to a clear path towards de-carbonization. This requires major installation of wind and solar power. However, these only provide intermittent electricity. Thus, balance power has to be provided, ideally from renewable resources. Currently besides pumped hydro storage only biomass seems to be available in large enough quantity to provide significant renewable balancing power. A wide range of biomass feedstocks can be made available for power generation for example via anaerobic digestion or thermo-chemical gasification. Yet, resources are still limited. Hence, in order to maximize its potential the biomass has to be used at the highest possible efficiency. Electrochemical conversion, especially in SOFC, in general offers very high efficiency. However, also in SOFC systems the choice of the optimal system design and operating parameters can make a big difference. The presented work investigates utilization of biogas and syngas from biomass gasification in different system designs. This is done using a thermodynamic SOFC model built in Aspen Plus, which has been validated against literature data. 


\section{SOFC model}

A detailed description of the SOFC model used in this work has been published in (1). The basic layout of the thermodynamic model is based on a model described in (2), while the cell parameters were taken from (3). Therefore, only a comparison to cell and stack performance of the well-known manufacturers Fuel Cell Energy (former Versa Power) and Forschungszentrum Jülich is presented in the following. For this purpose Figure 1 shows results obtained by Versa Power (4) and the SOFC model operating at identical temperatures, atmospheric pressure and pure hydrogen as shown in Table I.

TABLE I. Parameters for comparison of SOFC model with results from Versa Power.

\begin{tabular}{cc}
\hline Parameter & Value \\
\hline Temperatures & $600,700,800^{\circ} \mathrm{C}$ \\
Pressure & 1.05 bara \\
Anode inlet & $100 \% \mathrm{H}_{2}$ \\
Fuel utilization & $<10 \%$ \\
Cathode inlet & $21 \% \mathrm{O}_{2}, 79 \% \mathrm{~N}_{2}$ \\
Oxygen utilization & $<1 \%$ \\
\hline
\end{tabular}

As is observable, despite the model is based on single cell data, the performance is much lower than the experimental data from (4).

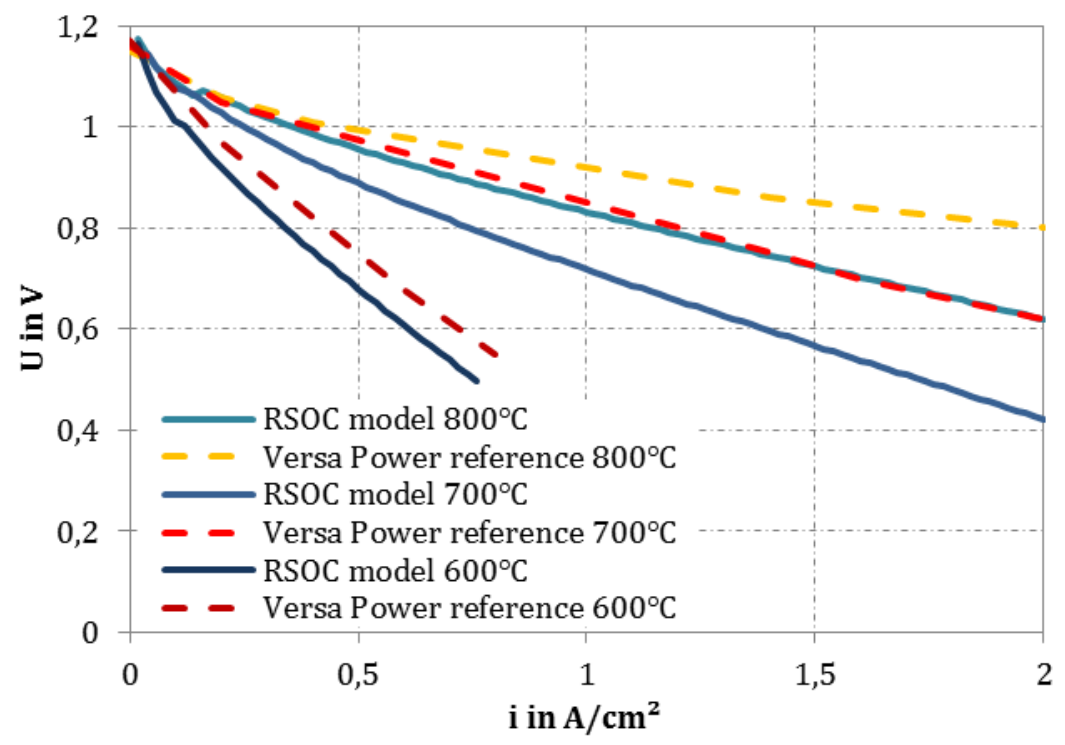

Figure 1. Comparison of the SOFC model and experimental single cell data from (4).

Thus a further comparison is shown in Figure 2. Here the model is operated at conditions as presented in (5), which are shown in Table II, for short stacks manufactured at the Forschungszentrum Jülich. As can be seen from the figure the model performance is almost identical to the stack performance at $700^{\circ} \mathrm{C}$, while at $800^{\circ} \mathrm{C}$ the real stack performs slightly better than the model. Overall it can be concluded that at identical operating conditions the model shows slightly worse performance than the real stacks. 
TABLE II. Parameters for comparison of SOFC model with results from Jülich.

\begin{tabular}{cc}
\hline Parameter & Value \\
\hline Temperatures & $700,800^{\circ} \mathrm{C}$ \\
Pressure & 1.05 bara \\
Anode inlet & $80 \% \mathrm{H}_{2}, 20 \% \mathrm{H}_{2} \mathrm{O}$ \\
Fuel utilization & $0-60 \%$ \\
Cathode inlet & $21 \% \mathrm{O}_{2}, 79 \% \mathrm{~N}_{2}$ \\
Oxygen utilization & $<1 \%$ \\
\hline
\end{tabular}

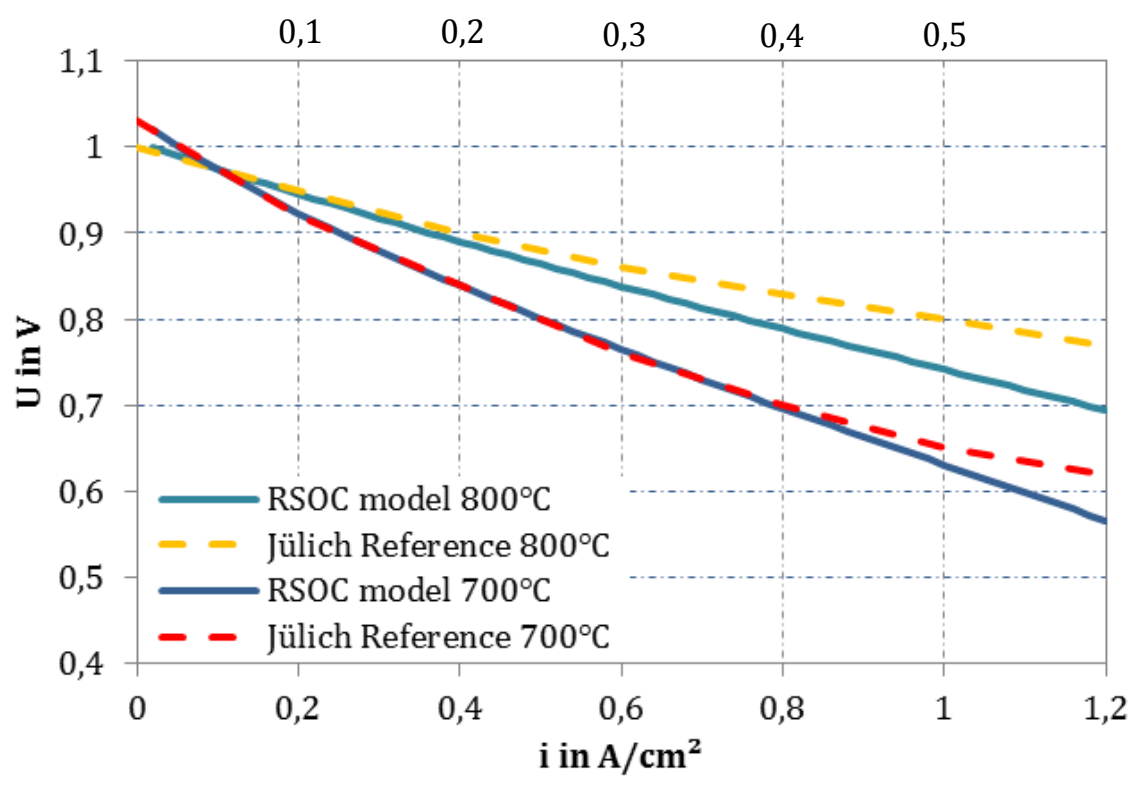

Figure 2. Comparison of the SOFC model and experimental short stack data from (5). The values shown at the upper $\mathrm{x}$-axis resemble the respective fuel utilization.

\section{System design and analysis}

In the following different system configurations are compared. Figure 3 displays a simplified drawing of the system layout under study. Air enters the SOFC cathode after compression to operating pressure and passing the air preheater. Fuel is also first brought to operating pressure, guided through a $\mathrm{ZnO}$ desulphurization bed, followed by the fuel preheater. Further gas cleaning measures are not investigated in detail, as described later. After passing through the SOFC the depleted air and fuel streams are mixed in a catalytic combustor. The combustor flue gas is split to supply both air and fuel preheaters with the required heat. Residual heat in the flue gas is assumed to be used for production of hot water or steam. Before entering the anode the fuel stream is:

(a) externally reformed by either auto-thermal catalytic partial oxidation (CPOX) using a small amount of preheated cathode air, or steam reforming (ext. ref.) by direct thermal coupling to the post-combustor

(b) mixed with a recirculated anode exhaust stream in order to promote internal reforming (int. ref.) 


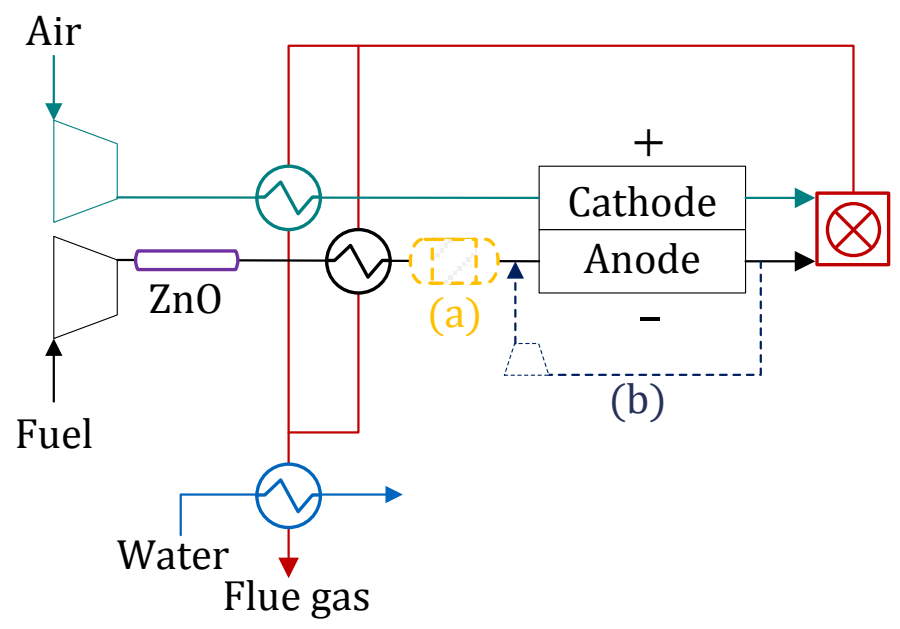

Figure 3. Simplified schematic drawing of the system layout.

Table III shows the general assumptions for the simulations. For the analysis the stack single pass fuel utilization (FU) is in always limited to $80 \%$, since inhomogeneity in the fuel distribution along the stack could otherwise cause severe degradation. Therefore higher global FU values are only achievable when using anode exhaust recirculation. Furthermore, for almost all cases the global FU is generally limited to a value where the anode exhaust still contains at least 5\%-mol. residual fuel.

TABLE III. General assumptions for the system analysis.

\begin{tabular}{cc}
\hline Parameter & Value \\
\hline Fuel inlet temperature & $750^{\circ} \mathrm{C}$ \\
Fuel outlet temperature & $800^{\circ} \mathrm{C}$ \\
Air inlet temperature & $700^{\circ} \mathrm{C}$ \\
Air outlet temperature & $800^{\circ} \mathrm{C}$ \\
Average operating temperature & $775^{\circ} \mathrm{C}$ \\
SOFC operating pressure & $1.05 \mathrm{bara}$ \\
SOFC active area & $100 \mathrm{~m}^{2}$ \\
Blower isentropic efficiency & 0.75 \\
Mechanical + motor efficiency & 0.95 \\
Inverter efficiency & $98 \%$ \\
Air composition & $21 \% \mathrm{O}_{2}, 79 \% \mathrm{~N}_{2}$ \\
Oxygen utilization & $\leq 50 \%$ \\
Fuel electrons input & $8.0 \mathrm{~mol} / \mathrm{s}$ \\
Single pass stack FU & $\leq 80 \%$ \\
Minimum outlet fuel concentration & $\geq 5 \%$-mol. \\
\hline
\end{tabular}




\section{Simulation results}

\section{Gasification syngas}

First of all the conversion of syngas from biomass gasification is studied. Since the gasification syngas typically exits the gasifier with a composition already close to thermodynamic equilibrium at $700-800^{\circ} \mathrm{C}$ basically no pre-reforming is necessary. Thus, after removal of contaminants ( $\mathrm{S}, \mathrm{Cl}$, tars and others) the syngas can be fed directly to the anode. Detailed analysis of gas cleaning is beyond the scope of this work. Relevant information can be found in refs. (6-8). The fuel composition, similar to (9), and fuel energy input can be seen in Table IV. The fuel flow is adjusted in order to achieve the same amount of electrons available for electrochemical conversion.

TABLE IV. Syngas composition from woody biomass gasification (9).

\begin{tabular}{cc}
\hline Parameter & Value \\
\hline Fuel power & $936.7 \mathrm{~kW}_{\mathrm{LHV}}$ \\
Fuel flow & $7.27 \mathrm{~mol} / \mathrm{s}$ \\
$\mathrm{H}_{2}$ & $25 \%$ \\
$\mathrm{CO}$ & $10 \%$ \\
$\mathrm{CO}_{2}$ & $10 \%$ \\
$\mathrm{CH}_{4}$ & $5 \%$ \\
$\mathrm{H}_{2} \mathrm{O}$ & $50 \%$ \\
\hline
\end{tabular}

Figure 4 shows the results of the parameter study for a system without recirculation and a recirculation rate of $50 \%(\mathrm{R}=0.5)$. These are results of the SOFC only, yet without including inverter losses and auxiliary consumption (mainly blowers).

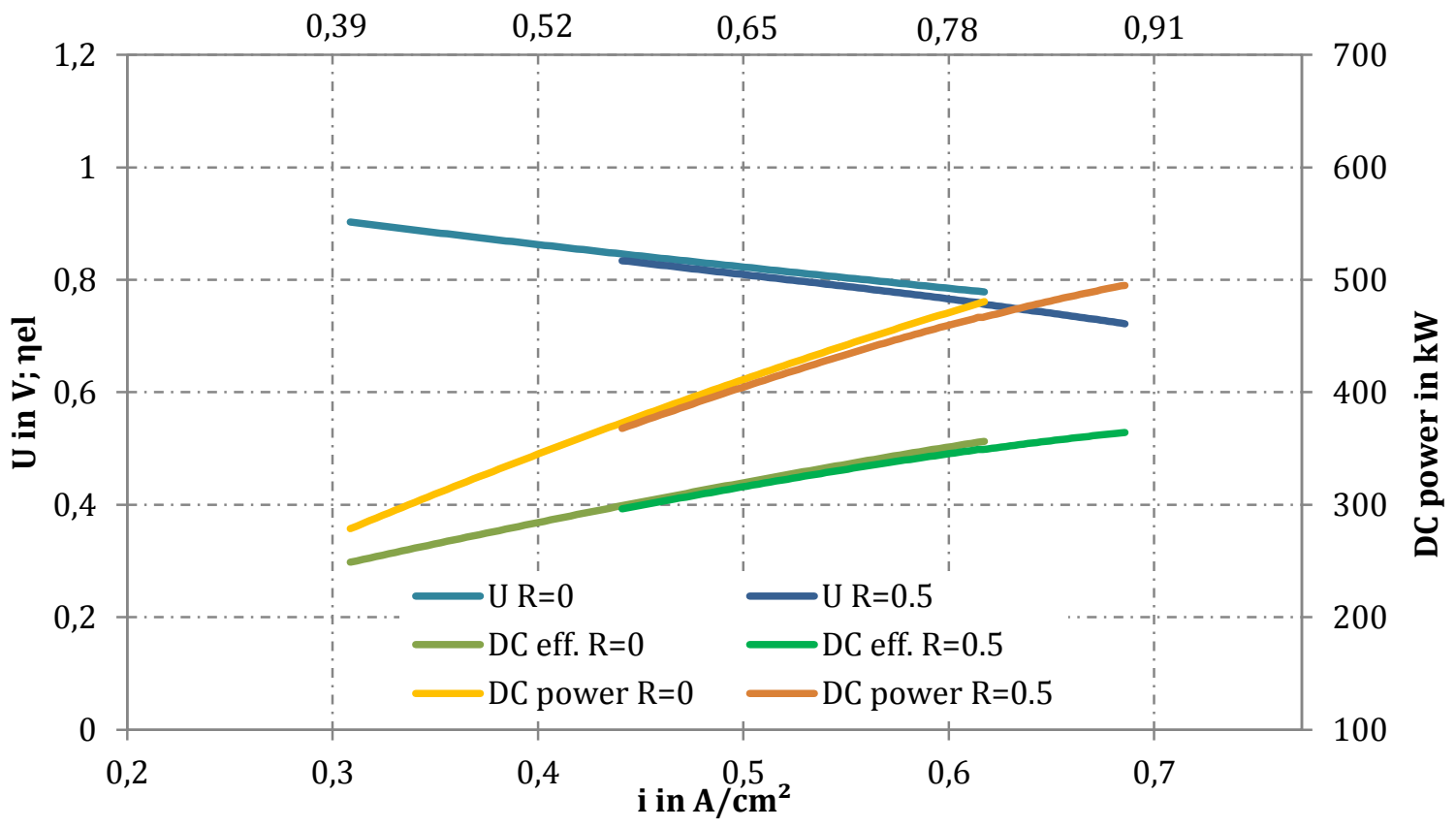

Figure 4. Results of the parameter study for SOFC operated on gasification syngas. The values shown at the upper $\mathrm{x}$-axis resemble the global fuel utilization. 
The results show that in the syngas case the recirculation rate slightly lowers the cell voltage due to the dilution with additional steam and $\mathrm{CO}_{2}$. Thus, until a global FU of $80 \%$ the system performs better without recirculation. However, due to the restriction to $80 \%$ single pass FU in order to achieve maximum power output recirculation is necessary. The maximum achievable global $\mathrm{FU}$ is $88 \%$, before the anode exhaust reaches the dilution limit.

Biogas from anaerobic digestion

In contrast to syngas biogas from anaerobic digestion mainly consists of a mixture of $\mathrm{CH}_{4}$ and $\mathrm{CO}_{2} . \mathrm{CH}_{4}$ concentrations typically range from $50-70 \%$. Here as a worst case scenario 50\% is assumed as displayed in Table V. It is already observable from the table that in order to achieve an equivalent amount of available electrons the required energy input (LHV) is much lower for biogas than for syngas. Also in this case detailed analysis of cleaning is beyond the scope. Further information biogas generation and cleaning may be found in (10).

TABLE V. Exemplary composition of biogas from anaerobic digestion.

\begin{tabular}{cc}
\hline Parameter & Value \\
\hline Fuel power & $802.7 \mathrm{~kW}_{\mathrm{LHV}}$ \\
Fuel flow & $2.0 \mathrm{~mol} / \mathrm{s}$ \\
$\mathrm{H}_{2}$ & $0 \%$ \\
$\mathrm{CO}$ & $0 \%$ \\
$\mathrm{CO}_{2}$ & $50 \%$ \\
$\mathrm{CH}_{4}$ & $50 \%$ \\
$\mathrm{H}_{2} \mathrm{O}$ & $0 \%$ \\
\hline
\end{tabular}

Figure 5 shows the performance results of the SOFC operated in with different reforming approaches as explained above. As is to be expected, using CPOX the performance is lower than for the other options, since a share of the fuel is already consumed during the auto-thermal CPOX. Despite the fact that the fuel energy content (LHV) does not significantly change during the CPOX, the exergy content in the form of available electrons is reduced by more than $24 \%$. Therefore the achievable maximum power density reduces. Furthermore the voltage is lowered by dilution of the fuel with combustion products and $\mathrm{N}_{2}$.

Comparing the cases of external steam reforming and internal steam reforming with anode exhaust recirculation several effects are observable. First of all the allowed FU range is very different for both cases. For external reforming the global FU is limited by the maximum single pass FU of the stack. In the case of internal reforming there is a minimum FU of about $75 \%$, which is determined by the risk of carbon deposition and too high air utilization for lower FU values. Secondly, for the internal reforming the I-V curve is shifted towards higher fuel utilizations. This is attributed to the recirculation of unconverted fuel, which overall increases the average concentration of fuel at equivalent global FU values and thus the Nernst potential. For internal reforming in the plot also an exception has been made to allow outlet concentrations of less than 5\%-mol. of residual fuel. Above a global FU of $88 \%$ (stack FU of $80 \%$ ) the recirculation rate is increased from 50 up to $90 \%$ (above $80 \%$ the outlet fuel concentration becomes $<5 \%$ ) in order to examine the dilution of the inlet fuel with the reaction products $\mathrm{H}_{2} \mathrm{O}$ and $\mathrm{CO}_{2}$ at very high 
global FU. Above a FU of $92 \%$ the dilution starts to dominate the I-V behavior and the overall power output decreases.

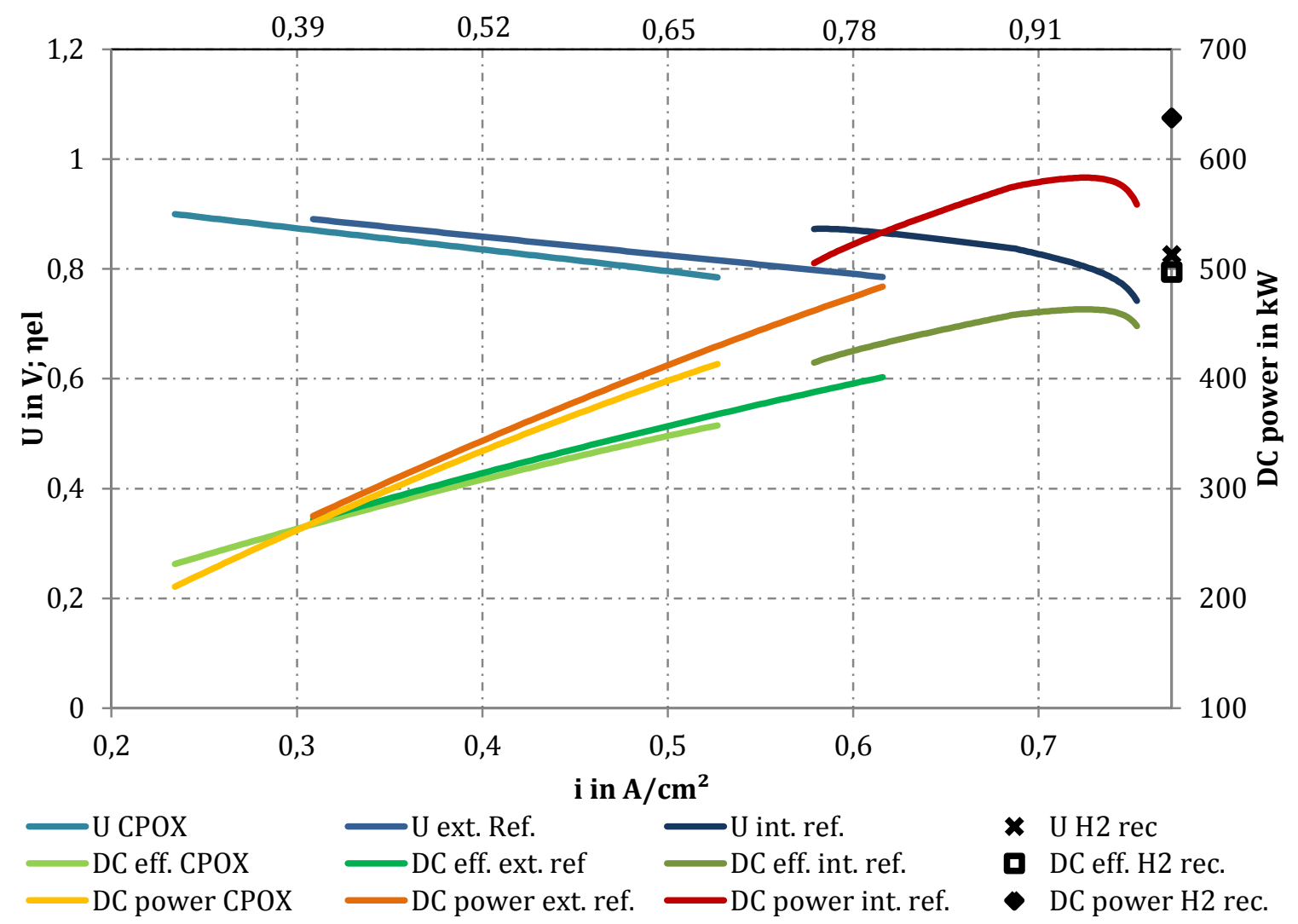

Figure 5. Results of the parameter study for SOFC operated on biogas from anaerobic digestion. The values shown at the upper $\mathrm{x}$-axis resemble the global fuel utilization.

To counter the dilution effect and enable a global FU of close to $100 \%$ Schlitzberger proposed a new system layout as shown in Figure 6 (11). Here this configuration is adapted for the conversion of biogas. The residual $\mathrm{CO}$ in the anode exhaust generated by internal/external reforming is converted in a water gas shift membrane unit, which is purged with the inlet biogas on the permeate side, according to Eq. 1.

$$
\mathrm{CO}+\mathrm{H}_{2} \mathrm{O} \rightarrow \mathrm{CO}_{2}+\mathrm{H}_{2}
$$

During this process the $\mathrm{H}_{2}$ permeates through the membrane into the biogas. Thus the residual available electrons are re-transferred into the inlet fuel thereby and again into the SOFC. Hence, ideally the global FU becomes independent of the stack FU and the anode exhaust recirculation rate and is only dependent on the separation efficiency of the membrane. Furthermore, using an ideal membrane finally pure $\mathrm{CO}_{2}$ can be obtained. Simulation results for this configuration with a stack FU of $50 \%$, an anode exhaust recirculation of $30 \%$, which is just enough to prevent carbon deposition, and consequently a $\mathrm{H}_{2}$ transfer of $2.8 \mathrm{~mol} / \mathrm{s}$ (to achieve $100 \%$ global $\mathrm{FU}$ ) are shown on the right side of Figure 5. For this first analysis the membrane is assumed as an ideal membrane, which exclusively permeates $\mathrm{H}_{2}$ without significant pressure drop. The simulation results are depicted in Table VI. Despite the high current density of 0.77 $\mathrm{A} / \mathrm{cm}^{2}$ due to the avoided concentration losses the operating voltage is $0.82 \mathrm{~V}$ and the 
calculated DC efficiency rises up to $78.8 \%$. This is $7.4 \%$-points higher than the maximum value for the anode exhaust recirculation case.

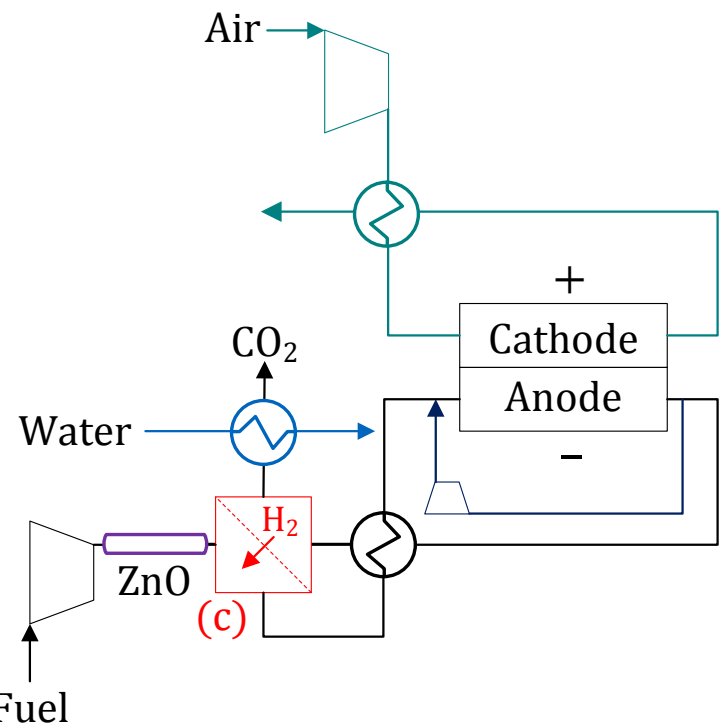

Figure 6. Simplified schematic drawing of SOFC system with water gas shift membrane and $\mathrm{H}_{2}$ recovery for increased fuel utilization.

TABLE VI. Simulation results for the SOFC system with $\mathrm{H}_{2}$ recovery.

\begin{tabular}{cc}
\hline Parameter & Value \\
\hline Operating voltage & $0.82 \mathrm{~V}$ \\
Current density & $0.77 \mathrm{~A} / \mathrm{cm}^{2}$ \\
DC output & $632.3 \mathrm{~kW}$ \\
Inverter losses & $-12.6 \mathrm{~kW}$ \\
Air blower & $-31.3 \mathrm{~kW}$ \\
Biogas blower & $-1.3 \mathrm{~kW}$ \\
Anode exhaust recycle blower & $-0.7 \mathrm{~kW}$ \\
Net AC output & $586.3 \mathrm{~kW}$ \\
Net AC efficiency & $73.0 \%$ \\
\hline
\end{tabular}

Considering auxiliary consumption by blowers and inverter losses the net AC output in this configuration reaches $586.3 \mathrm{~kW}$, which resembles a net efficiency of $73.0 \%$. The highest net AC efficiency calculated for the conventional internal reforming case is $64.3 \%$. The fairly low auxiliary consumption in both cases is due to the cooling effect of the internal reforming. In the external steam reforming case due to a larger cooling air demand because of the missing cooling effect the efficiency becomes only $49.0 \%$, whereas in the CPOX case the maximum AC efficiency is even as low as $43.1 \%$. For syngas operation also a very high cooling air demand is necessary. Furthermore as described above the exergy content of syngas is lower than for biogas. Therefore the maximum efficiency of the SOFC operating on syngas is calculated as $43.9 \%$. 


\section{Summary}

In this study several system configurations for utilization of biogenous fuels in SOFC are investigated using a thermodynamic SOFC model built in Aspen Plus. An initial comparison to experimental data from well-known manufacturers yields that the model performs similarly or slightly worse than state-of-the-art SOFC stacks. Based on this result the utilization of a typical syngas from biomass gasification, as well as typical biogas from anaerobic digestion is examined. In the case of syngas the original solid biomass fuel is already reformed. For biogas several different reforming options are investigated. Findings are that the efficiency largely depends on the type of fuel used, as well as the system configuration. Due to the requirement of large amounts of cooling air syngas and CPOX the maximum net obtainable efficiency found during the parameter studies is around $30-44 \%$. Steam reformed biogas enables efficiencies of up to $49 \%$, while internal reforming with anode exhaust recirculation can increase the efficiency to above $64 \%$. Since it is found that the internal reforming approach is essentially limited by the inability to convert all the fuel electro-chemically at high efficiency a new system configuration is adopted, which was first proposed by Schlitzberger (11). The system is based on recovery of unconverted fuel via a water gas shift membrane. Simulation results for this new configuration, based on the assumption of an ideal membrane behavior, show the potential to reach net efficiencies of up to $73 \%$ when operated on biogas.

\section{Acknowledgements}

Parts of the models used in this work have been developed within the FCH-JU project SOFCOM GA. Nr. 278798. The current SOFC research at the Chair for Energy Systems is funded within the project SynSOFC by the Deutsche Forschungsgemeinschaft (DFG), which is gratefully acknowledged. Furthermore the authors thank the State of Bavaria for supplementary funding.

\section{References}

1. M. Hauck, S. Herrmann and H. Spliethoff, Int. J. of Hydr. En., (2017).

2. B. Tjaden, M. Gandiglio, A. Lanzini, M. Santarelli and M. Vinnen, Energy. \& Fuels, 28 (6) (2014).

3. P. Kazempoor and R. Braun, Int. J. Hydr. En., 39 (11) (2014).

4. R. Petri, A. Wood, H. He, T. Joia, C. Brown, B. Borglum, E. Tang, M. Pastula and M. Richards, Reversible Solid Oxide Fuel Cell (RSOFCEL) Development at Versa Power Systems, ENE41-2 Solid Oxide Electrolysis Systems.

5. L. Blum, Q. Fang, N. Margaritis and R. Peters, Stack Development at Forschungszentrum Jülich, 12th European SOFC \& SOE Forum 2016.

6. M. Gaderer, S. Herrmann and S. Fendt, Gas Clean-up for Fuel Cell Systems Requirements \& Technologies, Wiley-VCH, Weinheim (2016).

7. S. Herrmann, M. Jimenez Arreola, M. Gaderer, and H. Spliethoff, ECS Trans,. 68(1), 277-282 (2015).

8. P.V. Aravind and W. de Jong, Progr. in En. and Comb. Sc., 38, 737-764 (2012).

9. M. Mayerhofer, P. Mitsakis, X. Meng, W. de Jong, H. Spliethoff and M. Gaderer, Fuel, 99, 204-209 (2012) 
10. M. Gandiglio, A. Saberi, A. Lanzini, M. Santarelli, ASME 14th International Conference on Fuel Cell Science, Engineering and Technology, (2016).

11. C. Schlitzberger, Solid Oxide Fuel Cell (SOFC)-Systeme mit integrierter Reformierung bzw. Vergasung von Kohlenwasserstoffen, Dissertation, TU Braunschweig (2012). 